\title{
Public Policy and Insurability
}

\author{
by R. L. Carter*
}

\section{The influence of public policy on insurance operations}

The intervention of government in the operations of the insurance industry has been justified on the grounds that it is "an industry affected with the public interest" [1], and Berliner asserts that if the industry wishes to defend its reputation in the eyes of the public it must uphold "the idea of insurance and of insurance ethics" [2]. So he goes on to argue that it is in long-term interests of individual insurers and of the industry that insurance should be provided only if it is consistent with "public policy", in accordance with the following definition in Black's Law Dictionary:

“... the community common sense and common conscience extended and applied throughout the state to matters of public morals, public health, public safety, public welfare, and the like; it is that general and well-settled public opinion relating to man's plain, palpable duty to his fellow men having due regard to all the circumstances of each particular relation and situation."

Although the principle may appear clear, its practical application presents various difficulties. There are in fact few hard and fast rules to guide insurers in deciding whether it would be contrary to public policy to provide insurance for particular risks, unless they happen to be associated with acts which have been ruled to be either criminal or illegal. However, whether to refuse to provide insurance or to pay claims in other cases, because to do so may seem to conflict with "general and well-settled public opinion", is often debateable.

The changes that occur in public opinion over time add a further complication: what previously may have been unacceptable behaviour may no longer be so, and vice versa, so that "public policy" is not an immutable constant. Furthermore, if a country's legislators have not been prepared to ban a particular act, why should an insurer refuse to enter into a contract in relation thereto?

* Norwich Union Professor of Insurance Studies University of Nottingham 


\section{The changing attitudes of society}

The concept of public policy is inextricably linked to ethics and morality. Ethics may be defined in terms of what people "ought" to do, or what it is "right" for them to do, or refrain from doing, so setting standards against which behaviour can be judged. Morality relates to behaviour, being that which closely conforms to the accepted ethical norm. In other words, "morality is the practice of ethics" [3]. Whether the standards to which mankind "ought" to adhere are absolute and immutable, or whether they are relative, depending upon the person, the circumstances and the time, has been the subject of endless philosophical debate. Pragmatically, however, the inescapable fact is that the standards of behaviour which a society accepts as the norm not only vary from country to country, but also change over time.

The relationship of morality to the laws enforced by a state raises other problems. Although the two may be closely related, they may not wholly coincide. For example, a crime has been defined as an immoral act, but:

- governments prohibit many acts on grounds of social expediency rather than immorality (for example, some acts that may be committed in the course of business have been classified as crimes mainly for the former rather than the latter reason); and

- acts which may be regarded as immoral may not necessarily be treated as a crime. Moreover, even if the majority of public opinion is in favour of treating a certain act as a crime, it only becomes so when the necessary legislation is enacted.

Two examples of behaviour towards which society's attitudes have changed radically this century are adultery and suicide. Although condemned in the Old Testament as warranting death by stoning, adultery long ago ceased to be a crime in most modern societies. Likewise, bowing to the change in public opinion, in 1961 the British Parliament decided that suicide while of sound mind, or any attempt to commit suicide, would no longer be treated as being criminal acts (Suicide Act, 1961). Other fundamental shifts of public opinion have occurred in relation to such matters as racial and sexual discrimination, and responsibility for environmental pollution, leading in due course to changes in the law.

Such changes in public attitudes and thus in what may be construed as public policy can affect insurers in several ways.

First, some of the changes that are occurring run counter to traditionally accepted insurance principles. The prime example would be the anti-discrimination provisions of race and sex discrimination Acts which may conflict with insurance premium rating principles.

Secondly, a change in attitudes and laws in one country does not necessarily mean that similar changes have occurred elsewhere, as is evidenced by the treatment of adultery under the full rigours of Islamic law. Thus what constitutes "public policy" is a matter for local interpretation, so that an insurer operating internationally cannot adopt one set of rules for the whole of his global operations.

\section{Insurance ethics}

Long lists nine societal attributes which he sees as forming the "ethical pillars" of insurance [4]. Included in the list are honesty and obedience (that is, a willingness to obey the law): both present him with a dilemma in that deviations from those standards of behaviour form 
the basis of the demand for certain classes of insurance, notably liability and theft insurances. $\mathrm{He}$ concludes that for insurance to function people generally must act honestly and be obedient to the law, and that any deviations therefrom must lie within tolerable limits. That begs the questions of what is tolerable, and whether the provision of insurance may encourage further deviation. The latter question embraces the phenomenon of moral hazard which lies outside the scope of this paper.

\section{Risks for which insurance should not be provided}

\section{(a) Insurance contrary to public policy}

Obviously an insurer should refrain from entering into any contract of a type that has been declared illegal, even if not criminal, either on the grounds of public policy or public morality. Apart from those contracts which an insurer in the course of his international operations may have entered into with persons residing in an enemy country prior to the outbreak of a war, there are few cases where insurance contracts would themselves fall within the class of contracts that in English law have been declared illegal either by statute or by the courts. However, there are cases where though the insurance contract itself may not have been illegal, the court has refused to enforce it on grounds of public policy. For example, in the case of Mackender vFeldia AG (1966) it was held that although an insurance contract effected to cover goods which were to be smuggled into a friendly country was not itself illegal, it would have been contrary to public policy to have enforced it. In a more recent case involving the same principle (Geismarv Sun Alliance and London Insurance Co. Ltd. (1977)), the policyholder had submitted a claim under his contents policies for the theft from his house of various articles, including a number of items which he had brought into the country deliberately without declaring them for the payment of customs duty. The court held that although the policies were not thereby illegal, it would have been contrary to public policy to have required the insurers to have indemnified the policyholder for the stolen articles because they would have thereby assisted him to derive a profit from his deliberate breach of the law.

The importance of insurers conforming to the dictates of public policy has even more force in those cases where the policyholder deliberately sets out to bring about a loss in order to claim against his insurers. In the classic case of Beresford v Royal Insurance Co. Ltd. (1938) the insurers refused payment under a life policy because the policyholder, who was badly in debt, had deliberately shot himself. He was found to have committed suicide while of sound mind, which at that time still was a criminal act, and the court held that it would be contrary to public policy to allow a man, even through his personal representatives after his death, to benefit from his crime. Likewise a policyholder who commits arson by deliberately setting fire to his own property in order to obtain the fire insurance monies would also be guilty of fraud if he proceeded to seek an indemnity from his insurers. Any relaxation of the law would inevitably tend to increase the incidence of arson and other acts of wilful destruction of property. However, attitudes do change, as noted above in the case of suicide, and in the opinion of many lawyers, insurers would now have to pay a claim for suicide in the absence of either a suicide clause in the policy or the non-disclosure of a material fact at the time the insurance was effected [5]. Moreover, the Forfeiture Act, 1982, opens the possibility of cases where an individual who unlawfully kills another may be allowed to benefit under a policy effected on the latter's life, other than in a case of murder [6]. 
Before leaving this point, it is worth noting that although the law may be clear that a policyholder should not be allowed to collect from his insurers for losses caused by his own deliberate act, it may also place obstacles in the path of insurers who seek to prevent that happening. In the United States insurers are wary of contesting doubtful claims: in 1984 the Insurance Information Institute reported that:

"The increasing number of punitive damage and bad faith law suits are presenting dilemmas to companies as they decide between contesting suspicious fire claims or just settling them." [7]

The institute went on to report that in order to try to deal with the problem, in 1980 it started a computerised record of fire and theft claims to which 778 insurance companies subscribe. It also urged more states to enact arson reporting immunity laws along the lines of the 1977 model law drafted by the National Association of Insurance Commissioners and the Insurance Committee for Arson Control which would permit the reciprocal exchange of information between insurance companies and law and fire investigation agencies.

\section{(b) Trivial losses}

If the concept of public policy is broadened beyond the strictly legal interpretation to embrace the public's economic welfare, then anything that affects the efficient use of resources also must fall within its ambit. It then follows that Berliner is right to question the provision of insurance against trivial risks. In his list of principles relating to insurability, he states in Principle 22 that the: "Covering of risks for which no real need for insurance exists is inconsistent with public policy" [8]. There are two issues which lead him to that conclusion.

First, there is the waste of resources involved in the provision of such insurances. Tobias in criticising American insurers for absorbing in expenses what he sees as an unjustifiably high proportion of the premium dollar, argues that part of the reason lies in insurers providing cover for, and handling large numbers of, trivial claims [9]. He cites the Insurance Service Office statistics that 60 per cent of the homeowners' policy claims paid in 1980 to people with $\$ 100$ deductibles were for less than $\$ 400$ and another 15 per cent were for less than $\$ 1,000$. He adds that:

"Eliminating 85 per cent of the claims would have eliminated just 30 per cent of the actual dollars insurers paid out to policyholders, as it is the relatively few large losses that account for most of the claim dollars paid - and for which insurance is both indispensable and efficient." [10]

Secondly, there is the impact of such insurance on the attitudes of policyholders. Berliner contends that the relatively high premiums that have to be charged to cover the cost of trivial claims "act as an incentive to dishonesty" for some policyholders who may attempt to recoup their premiums by lodging fictitious claims, especially if they know that small losses are not subject to thorough investigation. That hypothesis is supported by the experience of U.K. insurers in regards to travel insurances where many claims by holidaymakers for the loss of, or theft of, clothing and personal effects are due to carelesness or suspected by the insurers as being in some way fraudulent. One major insurer has responded by excluding from its travel insurances any cover for cameras, jewellery, etc., arguing that if insurance is required for such items it is more appropriately provided by means of a permanent "all risks" item on the individual's household policies, which is one of the solutions to the general problem considered by 
Berliner. However, his preferred solution is for insurers to make all policies subject to a minimal deductible and to encourage policyholders to take larger deductibles in exchange for commensurate reductions in the premium.

Small deductibles may help but they do not solve the problem. As Tobias points out, claims may then be inflated to ensure that there is some recovery from the insurers, but that practice becomes progressively less feasible as deductibles are increased in size [11]. The imposition of compulsory large deductibles would, however, run into other problems, which Berliner acknowledges. 'Trivial' is relative, varying in amount according to an individual's financial position and his attitude to risk, so that what constitutes a 'trivial loss' has for each individual both an objective and subjective dimension. A wealthy man can absorb without undue financial strain a larger loss than a poor man, but may have an aversion to doing so. Attitude, however, can to some extent be changed by education and information. If insurers and insurance intermediaries were less concerned with maximising premium income and more with the efficient operation of insurance business, then they would place more emphasis on advising both members of the public and small businessmen that insurance is an efficient way of handling only those uncertain losses of a size that could cause severe financial strain, and encouraging them to take higher deductibles. In order to help people to provide for small losses falling within the deductible, Tobias advocates that savings institutions and commercial banks should offer 'Self-Insurance Accounts' [12]. An alternative form of financing could be for such institutions to offer contingency loans [13], perhaps in conjunction with the 'SelfInsurance Account': both systems would be a more efficient way of handling small uncertain losses than insurance. With the changes that are occurring in the financial services industry, insurers are increasingly likely to find themselves in competition with other institutions that recognise the need for imaginative, more efficient, risk financing schemes for the handling of small losses.

Another facet of the provision of insurance against 'trivial' risks which was criticised by Tobias is the marketing of insurance against risks with very low probabilities of occurrence but which are only a sub-set of a more general, substantial risk. The classic example is airport travel insurance providing cover against accidental death and injury whilst travelling. For an individual who has a need for such financial protection, the cause of his premature death or injury is immaterial: he needs the full protection afforded by a life policy combined with a permanent disability insurance. By fragmenting insurance needs into small packages, the industry is adding to its administrative costs, thereby wasting resources, and it is failing to educate the public in the efficient use of insurance.

\section{(c) "Speculative risks"}

Berliner also includes "speculative" entrepreneurial risks in the classes of risks for which, in general, he considers that it would be contrary to public policy for insurers to provide insurance, on the grounds that to do so would not be "compatible with the idea of insurance" [14]. Whether he is referring to the generally held view that insurance can only satisfactorily handle "pure" risks, or whether he is implying that "speculative" risks do not meet his criteria for insurability (e.g. that they are not random), is not made clear. However, rather than arguing that it would be contrary to public policy for insurers to try to extend the range of insurances provided to include speculative risks, such a development could be regarded as being in the public interest if it encouraged more enterprise and innovation leading to the faster growth of a country's economy. 
Speculative risks do, however, fall into a number of categories. There are some risks common to all business operations, including:

- risks arising from changes in the determinants of both the demand for firms' products/services and of the supply of their inputs;

- financial risks, including the availability and cost of credit;

- political risks;

and in the case of firms selling to, or importing from, or otherwise operating abroad:

- fluctuations in exchange rates and changes in exchange controls.

There are also risks associated with:

- attempts to enter markets, or to expand a firm's existing scale of operations whether by internal growth or by acquisition; and

- product or process innovation.

It is sound business policy for any firm to seek to control, in a manner consistent with its corporate objectives, every type of risk to which it may be exposed. Through the use of insurance and other devices, such as futures and traded options contracts to reduce the risk of adverse fluctuations in exchange rates, interest rates or commodity prices, firms are able to engage safely in more risky ventures than otherwise would be possible without a substantial increase in their capital resources. By providing insurance against risks that previously were regarded as unsuitable for insurance, insurers are both following the general trend of financial institutions in developing new contracts for the handling of risks, and continuing their own process of product innovation that over the last century has taken them increasingly into areas of risk closely bordering on speculative risks. For example, products liability and professional indemnity insurances reduce the risks to firms of product innovation, and by providing contract guarantees, insurers assume the risk of the failure of contractors to fulfil the terms of the contracts into which they enter.

There is nothing unethical in an insurer as a professional risk bearer relieving a firm of some of the risks of failure in its business operations. The practical issue is whether the risks which it is being asked to insure are such that:

- the loss making event is both random and largely outside the policyholder's control;

- there is sufficient information available to the insurer to enable him to estimate the loss expectancy and so rate the risk; and

- he is able to control his maximum possible loss both in respect of the individual risk and any possible accumulation of losses due to the occurrence of some event affecting a number of policyholders.

Certain risks of a speculative nature will fail to meet those conditions. For example, the risks of the marketing success or failure of either a new firm or the launching of a new product are in each case unique and to a high degree dependent upon the particular firm's own management skill and effort, so placing such risks beyond the ability of an underwriter to rate. Therefore, whilst recognising that some speculative risks are incompatible with the principles of insurance, insurers do fulfil a valuable economic function in extending the range of insurances they offer to embrace some risks of a speculative nature, thereby helping firms to reduce some of the risks of business enterprise and innovation. As with any other risk where the 
insured event may be significantly influenced by the insured's own behaviour, the insurance should not provide full protection but should leave the insured to participate to some degree in any loss.

\section{(d) Insurance and social behaviour}

Berliner deals with two other situations bearing on matters of public policy.

The first is where the provision of insurance may eventually lead to a situation where it becomes contrary to public policy for insurers to continue to offer insurance. The examples he gives fall into two categories:

- those where the policyholder himself dishonestly inflates, or colludes with a third party in inflating, the size of a claim; and

- where a third party (e.g. a vehicle or other repairer, doctor, etc.) inflates his charges in the knowledge that it is covered by insurance, and the insured for his part feels no obligation to challenge the amount.

Probably the escalation in court awards for personal injury, especially in those countries where the amount is decided by a jury, is to some extent a further manifestation of the attitude that insurers can afford to pay.

Many of the measures proposed by Berliner to combat the problem are already fairly standard practice, and the advances occurring in information technology are enabling insurers to operate more efficient systems of claims control; for example, by using computers to check vehicle repair estimates against spares parts prices and standard repair times. Recently the largest British motor insurer has taken the step of acquiring an interest in a group of vehicle repairers so that it will be able to exercise even closer control over repair costs. Partly it is a problem of moral hazard to which the most efficient solution is the use of coinsurance provisions in policies, as demonstrated by Arrow [15].

Educational campaigns by insurers and closer investigation of claims costs themselves add to insurers' expenses, so that if insurers are not to lay themselves open to more criticism of administrative inefficiency, they must attempt to balance any increase in expenses against the savings to be made in claims costs. Although in practice it may be relatively easy to estimate marginal expenses, the marginal reduction in claims costs is more difficult to evaluate.

The second issue discussed by Berliner is that of risks which may become unsuitable for insurance because of external circumstances, notably crime, terrorism and social unrest. Under this heading he includes two distinctly different situations, i.e.:

(i) an increase in crime and social unrest which erodes the random element of losses as the probability of the event occurring approaches certainty; and

(ii) the possibility of insurance itself acting as an incentive to crime.

In the case of (i) often the question of public policy arises not in relation to insurers supplying insurance but if they become unwilling to do so. That issue is discussed below.

The charge that the availability of insurance may contribute to an increase in criminal activity can be levied against many classes of insurance. Almost one hundred years ago, Clark in speaking of fire insurers observed that:

"... in view of one of their effects, they may be said to be created for the purpose of increasing the number of buildings destroyed by fire." [16] 
Clark was concerned principally with moral hazard on the part of policyholders, but sometimes the availability of insurance may be an additional factor that motivates others to commit criminal acts. On occasions thieves, for example, offer the excuse that an insurance company rather than their victims will ultimately pay for the costs of their crimes. However, as noted by Berliner, the most contentious class of insurance today is kidnap and ransom insurance which has been made illegal in several countries on the grounds that it encourages kidnapping by terrorists and other criminals if they know that there will be readily available funds to meet their ransom demands. The counter-argument is that the loss prevention and claims control efforts of insurers equally act as a deterrent to criminals. Kidnap and ransom insurance is only provided subject to the agreed security measures being observed, and in the event of a kidnapping expert negotiators employed by the insurers will, in co-operation with the authorities, handle all negotiations for the victim's release.

To argue that an insurer should never provide insurance if it could conceivably act as an incentive to criminal behaviour would unduly restrict insurers in meeting the demand for insurance. However, where there is a substantial risk that insurance could incite people to crime, it is in the public interest not that insurance should be refused but that the measures proposed by Berliner should be observed [17].

\section{Risks which it may be contrary to public policy not to insure}

\section{(a) Compulsory insurances}

Almost all governments have enacted laws requiring insurance to be effected against certain types of risk, notably:

(i) the liability of motorists for injury to third parties; and

(ii) the liability of employers for injuries sustained by employees in the course of their employment.

The trend is for governments to extend the range of compulsory insurances to other risks, usually (though not exclusively) against liabilities to third parties, as a condition for allowing specified hazardous activities to be undertaken.

Such legislation places an onerous duty on insurers because an individual or firm refused insurance is debarred from legally undertaking the particular activity, even if otherwise licensed by the state to do so. Thus it might be argued that by refusing insurance, the insurance industry collectively would be acting contrary to public policy.

In the United States, for example, the inability of some high risk motorists to obtain compulsory automobile liability insurance led to complaints in political circles, and the "insurance industry realized that some program for the uninsured had to be developed" [18]. Two solutions were considered: one was a form of pooling arrangement for premiums and losses in which all insurers would participate; the other was to assign specific risks to individual insurers in proportion to the amount of voluntary business each insurer wrote in the state, subject to uniform premium rates and policy coverage and conditions. In 1938 New Hampshire was the first state to adopt an assigned risk plan, and similar plans or other market sharing systems are now in operation in all of the states.

Reinmuth and Stone in their 1970 study of assigned risk plans recognised that at the root of the problem was the failure of the legal system "to remove the majority of so-called bad 
risks' from the roads". However, the provision of insurance is no substitute for banning bad drivers from the roads, nor has it proved to be even a second best solution to a social problem. Although the premiums charged under the plans have been higher than for other drivers, they have generally been insufficient to cover costs, so that assigned risk drivers as a group have been subsidised by other motorists. Reinmuth and Muller opined that some form of subsidy would always be necessary because "Individuals in this market in many cases cannot afford the premiums necessary to make this business break-even". If Doherty is correct in believing that premium rates can influence loss prevention behaviour [19], it follows that the subsidising of high risk drivers reduces the incentive for them to drive more safely. Thus the provision of subsidised motor insurance to high risk drivers may increase their private welfare, but the overall result will be to reduce public welfare in that it will tend to increase the number of road accidents.

\section{(b) When the social benefit of insurance exceeds the private benefit}

Following an examination of the relationship between rising population density in urban areas and crime rates, Long described the implications for insurance of rising crime rates as follows:

"... theft might become a peril no longer susceptible to insurance treatment because of the intolerably high frequency and severity of losses. Before this type of insurance would be withdrawn from the market, we might see the deductibles consistently enlarged, urbanized territories increasingly excluded, and the list of uninsurable properties considerably broadened." [20]

In fact Long was describing what was already happening because American insurers had begun to "redline" districts in the 1960 s as social unrest and crime mounted in the inner city areas. By doing so they not only deprived policyholders of protection at the time when they increasingly needed insurance against risks which they could not themselves control, but the withdrawal of insurance also helped to accelerate the rate of urban decline by providing one more incentive for those individuals and firms that could afford to move to safer areas to do so. Thus the total social benefit lost due to the widespread withdrawal of insurance exceeded the aggregate private benefit lost by individual policyholders. The commissioners of insurance in several states responded by prohibiting insurers from cancelling the policies of inner city area residents.

In 1968 the President's National Advisory Panel on Insurance in Riot-Affected Areas included in its recommendations the introduction of the 'fair access to insurance requirements' (FAIR) plans to provide urban core property owners with comprehensive insurance coverages at premium rates which ignored the environmental hazards. Thus the additional cost of inner city claims would be subsidised by other policyholders. It is a policy which not only conflicts with the insurance principle of fair discrimination in premium rates, but also fails to go to the root of the problem of urban decay and social unrest, which is a problem for the whole of society. If the subsidisation of inner city residents is seen as one way of helping to regenerate such areas, the burden should fall on the whole body of taxpapers and not just on policyholders. It is not the function of private insurance to act as an income redistribution mechanism: that is a task for the state. Therefore, if social policy dictates that insurance should continue to be provided at uneconomic premiums, either private insurers should be 
recompensed by the state so that the cost is not borne by other policyholders, or a state agency should either itself underwrite the business or provide insurers with some form of stop loss reinsurance.

\section{Conflict between public policy and insurance principles}

As noted earlier, traditional insurance practice is being questionned as public attitudes change, notably on matters of discrimination between individuals.

The practice of insurers discriminating between men and women in premium rates and/ or policy benefits has been challenged in both American and British courts under the provisions of sex discrimination laws. In the case of Arizona Governing Committee vs Norris (1983), the United States Supreme Court held that although annuity contracts which discriminate on the basis of sex are legal, employers are prohibited from offering them to employees, even as an option, under a contract of employment. In Britain the court upheld the right of an insurer, on the basis of actuarial evidence of differing morbidity rates between men and women, to charge a woman a higher premium for permanent disability insurance (Pinderv Friends Provident Life Office (1985)). Although in both countries the courts upheld the insurance principle of fair discrimination between policyholders on the basis of objective evidence of differences in loss expectancies between identifiable groups, there is continuing pressure for the abandonment of the practice. Several unisex insurance bills have appeared before the U.S. Congress, and some states have passed laws requiring no discrimination between the sexes in automobile insurance premium rates. In Britain the Equal Opportunities Commission continues to oppose all sex discrimination in insurance contracts, and the European Economic Community has issued a directive to end discrimination in pension contributions and benefits.

The pressure to redefine "unfair" discrimination is broader than questions of sex and race. Part of the argument used in the Arizona case was that even if on average there were differences between men and women as groups, there was no proof that the plaintiff would impose a higher cost on the annuity fund than one of her male colleagues. Such an argument goes to the very foundations of insurance principles, and if accepted would necessitate uniform premium rates for all policyholders. If that is what society wants, then discrimination in premium rates could become contrary to public policy. As Long observed in his discussion of the principles underlying the FAIR plans:

"Laws can be reinterpreted; statutes can be reworded. If the public, because of a change in its ethical thinking (or any other reason), wants to share insurance losses on a wider basis in the hope of solving social problems, changes can be made fairly easily in the way insured losses are averaged." [21]

Non-discrimination in contributions is a common feature of social security systems, being justified on the grounds of both administrative efficiency and the principle that social risks, such as unemployment, industrial accidents and sickness, should be pooled over the whole of society. Beveridge in his 1942 Report on Social Insurance enunciated six fundamental principles, including a flat rate of subsistence benefit and a flat rate contribution: regarding the latter, he said:

"The second fundamental principle of the scheme is that the compulsory contribution required of each insured person or his employer is at a flat rate, irrespective of his means. 
All insured persons, rich or poor, will pay the same contributions for the same security; those with larger means will pay more only to the extent that as tax-payers they pay more to the National Exchequer and so to the State share of the Social Insurance Fund ... Subject moreover to one exception, the contribution will be the same irrespective of the assumed degree of risk affecting particular individuals of forms of employment." [21]

The proposed exception was a special levy on employers in high risk industries proportionate to risk and payroll. It arose out of Beveridge's acceptance of the argument that flat rate contributions would provide no incentive for employers to seek to reduce the risks of industrial accidents. However, that proposal was not adopted by the government, and the pooling principle over-rode the need to strengthen incentives for risk reduction.

It is arguable that the pooling of risks without any discrimination between participants on the basis of their loss expectancies can only work satisfactorily if participation in the scheme is compulsory. Otherwise there is an incentive for low risk individuals to seek other more efficient means of handling their risks, so that self-selection against the insurer will occur. And in a competitive insurance market there is every incentive for an insurer to find differences in the loss expectancies of sub-groups within the rating groups employed by competitors [22].

Berliner objects to the spreading of losses over various "more or less independent homogeneous groups of insured" as infringing "the principle of collective fairness". What is or is not "fair" is a normative question. Although one might accept the judgement of society that it is unfair to discriminate on the basis of characteristics over which the individual clearly has no control, such as gender or race, any breach of the insurance practice of discriminating between groups on the basis of objective evidence of differences in loss expectancies could ultimately lead to its total abandonment. As observed above, that would conflict with the public's interest in reducing the incidence of events that cause personal injury and death, and damage to property. Therefore, it is a trend in public opinion, and thus in public policy, which the insurance industry should resist.

\section{Conclusions}

There can be no question that the insurance industry should operate in conformity with the general principle of public policy. However, in practice it is not always easy to distinguish whether in particular cases the provision of insurance or the payment of a claim would be contrary to public policy, a difficulty exacerbated by the shifts that occur over time in public opinion. Also some developments in the area of public policy conflict with both well-established insurance principles and other aspects of the public interest.

There is an onus on insurers and insurance intermediaries to operate efficiently, and the developments occurring in the financial services industry will exert greater competitive pressure on them to do so. Nevertheless there will be a continuing responsibility on the industry to educate the public in the efficient use of insurance as a method for handling only the risk of financially crippling losses.

Finally, it cannot be construed as contrary to public policy for the industry to resist any changes in practice which, though in accordance with changes in public opinion and eventually in policy policy, may themselves impose an offsetting substantial cost on society. 


\section{REFERENCES}

[1] German Alliance Insurance Company v Lewis 233 U.S. 380 (1914).

[2] Baruch Berliner, "Limits of insurability of risks", p. 78, Prentice-Hall, Inc. 1982.

[3] John D. Long, "Ethics, morality and insurance", p. 3, Bureau of Business Research, Indiana University, 1971.

[4] Ibid, pp. 26-40.

[5] John Kilby, "Life insurance policies and public policy", Policy Market, February 1984.

[6] John Kilby, op cit, March 1984.

[7] Insurance information Institute, Insurance 1ssues 1984, public policy issues affecting Property/ Casualty Insurance.

[8] Baruch Berliner, op cit, p. 81 .

[9] Andrew Tobias, "The Invisible Bankers", pp. 152-157, The Linden Press, 1982.

[10] Ibid, p. 153.

[11] Ibid, p. 155.

[12] Ibid, p. 157.

[13] See, for example, the discussion of contingency loans in R.L. Carter and N.A. Doherty, "Insurance and risk retention", Handbook of Risk Management, Kluwer Publishing, 1974 (updated).

[14] Op cit, p. 81.

[15] K.J. Arrow, Aspects of the Theory of Risk Bearing, Helsinki, 1965.

[16] J.B. Clark, "Insurance business and profit”, Quarterly Journal of Economics, vol. 7, 1892.

[17] Ibid, p. 90.

[18] D.F. Reinmuth and G.K. Stone, A Study of Assigned Risk Plans, U.S. Government Printing Office (1970).

[19] Neil Doherty, Insurance Pricing and Loss Prevention, Saxon House.

[20] Op cit, pp. 96-97.

[21] Op cit, p. 117.

[22] Sir William Beveridge, Report on Social Insurance and Allied Services, para 305, Cmd. 6404, HMSO, 1942.

[23] H.M. Scurfield, "Motor insurance statistics", Journal of the Institute of Actuaries Students Society, vol. 18 , part. 3, 1968. 